Jacek Tadeusz Waliński

University of Lodz, Poland

\title{
Relevance of Linguistic Landscape to Intercultural Competence Development in the context of Situated Learning
}

\section{Introduction}

The concept of Linguistic Landscape (LL) was introduced in sociolinguistics by Landry and Bourhis (1997: 25), who described it as follows:

The language of public road signs, advertising billboards, street names, place names, commercial shop signs, and public signs on government buildings combines to form the linguistic landscape of a given territory, region, or urban agglomeration.

This description is nowadays regarded (e.g. Gorter, Marten \& van Mensel 2012) as the reference point for many of current developments in this field. Moreover, Cenoz and Gorter (2008) explore the role of linguistic landscape as an additional source of input in the Second Language Acquisition (SLA). They observe that linguistic landscape is not only multimodal (by combining visual and printed texts), but also multilingual, because of the variety of observed languages. For that reason, it can be used as a particularly valuable context for the acquisition of pragmatic competence, which can be employed in different manners for raising multimodal and multicultural awareness in the SLA.

This paper demonstrates that language landscape approach can also be successfully employed for intercultural competence development, which has 
been already perceived for some time (LACE 2006, CEDRPC 2006, RHLEFM 2008, CEDEFOP 2009) as a key qualification required of individuals to act effectively in the modern world. Application of the LL approach in the tertiary education contributes the crucial aspect of learning contextualization to the educational process (Biggs 2003). Moreover, it enables putting intercultural competence development in the context of intended outcomes outlined in the curriculum, and motivates students to participate in learning.

Research discussed in this paper is based on practical implementations of the linguistic landscape methodology in teaching intercultural competence, which were conducted in the context of both foreign, i.e. unfamiliar to participants (Walinski 2013a), and local (Walinski 2013b) environments. While the legitimacy of cultural diversity exploration in foreign locations is obvious, conducting such activities in local environments is based on an observation that "people who live in a particular country do not know intuitively or otherwise the whole of the culture of that country because there are in fact many cultures within a country" (Byram, Gribkova \& Starkey 2002: 17). This paper discusses results of pilot studies demonstrating that the language landscape methodology implemented in teaching with proper interaction, collaboration, and interpretation of results contributes to the development of intercultural competence in both such contexts.

\section{Linguistic Landscape}

Multiculturalism is manifested with multilingualism. The mutual link between cultural and linguistic diversity is stated in the Universal Declaration of Cultural Diversity (UNESCO 2001) and the Convention on the Protection and Promotion of the Diversity of Cultural Expressions (UNESCO 2005). The linguistic, hence cultural, diversity can be studied efficiently with the linguistic landscape methodology, which is a rapidly growing area of research that has recently gained enormous popularity in a variety of disciplines. It can be essentially defined as systematic examination of written displays of minority languages in the public space (Shohamy \& Gorter 2009).

A central position in LL studies is occupied by investigations of multilingualism, which is often manifested through the presence of minority languages in the linguistic landscape of a given region (Gorter 2006: 81-82). Since the linguistic landscape is an entirely human-made phenomenon, it evidently pertains to cultural reality of a given location. For that reason, it can be used to investigate how a particular linguistic landscape reflects languages used at a given location to discover its underlying cultural diversity. This makes a valid starting point for the cycle of intercultural competence development.

The linguistic landscape approach to intercultural and crosslinguistic studies involves counting languages on written signs in the streets inside and 
outside various types of buildings and subjecting them to different levels of linguistic analyses. Additionally, it can be augmented by qualitative data analysis in the form of background interviews, and thorough examination of collected language samples. Combined with other sources of data, such as information on spoken language traditions in a given region or language legislation, systematic examination becomes more comprehensive, as it takes into account ways in which the linguistic landscape reflects language demographics, attitudes and policies (Gorter, Marten \& van Mensel 2012: 3-4).

An important aspect in the linguistic landscape research is the notion of minority language in the focus of attention. It can be approached from different perspectives. One major distinction made by Gorter (2006: 5-6) distinguishes autochthonous (or traditional) and migrant (or new) minority languages, although as stressed in studies on multilingualism in Europe (Extra \& Gorter 2008: 9) those groups have much more in common than is usually noticed. Another important distinction (Gorter, Marten \& van Mensel 2012: 6) is the differentiation between unique minority languages, i.e. languages which exist only as minority languages (such as Basque or Welsh), and local-only minority languages, which are majority languages in another state (such as Polish in Lithuania). As emphasized in the above studies, such distinctions are not always easily applicable in real-life situations, therefore they remain arbitrary in certain contexts. By exploring reciprocal relations among ethnic groups the linguistic landscape investigation contributes to better understanding of the dynamics of cultural diversity changes in different regions.

Another fundamental point of discussion in the current linguistic landscape research concerns the unit of analysis. Although all linguistic landscape studies take into consideration language sings, there are different views on what should be considered a valid language sign. Backhaus (2007: 66) defines it quite broadly as "any piece of written text within a spatially definable frame". Most linguistic landscape studies are based on static linguistic signs. However, as argued by Gorter, Marten \& van Mensel (2012: 6), this perspective may be somehow outdated nowadays when, especially in urban regions, we are often surrounded by flat screen displays and other dynamic visual signs that have recently gained enormous popularity.

Furthermore, Gorter (2006) points out another category of written language signs, which includes moving signs, such as texts on cars, buses, clothing, bags, and other items that people carry around in a particular area. They certainly contribute to the observable linguistic landscape, too. The discussion on the unit of analysis is still far from reaching a definitive conclusion. When confronting a particular situation, researchers and practitioners often face the necessity to take arbitrary decisions about what should, and what should not be taken into consideration. Fortunately, the linguistic landscape methodology provides plenty of flexibility in this respect, which enables practitioners to decide which elements should be included, depending on the particular context of study. 
Over the past decade, the linguistic landscape approach has gained prominence not only in sociolinguistics, but also in other disciplines, theoretical frameworks, and methodologies. For example, it was employed successfully in econometrics (e.g. Nunes, Onofri, Gorter \& Cenoz 2008), political science (e.g. Sloboda 2009), tourism (e.g. Kallen 2009), as well as other fields of research. In linguistics, research employing linguistic landscape goes along different directions. Apart from the above mentioned applications in the SLA (Cenoz \& Gorter 2008), other efforts focus on the situation of minority languages in different regions (Cenoz \& Gorter 2006), multilingualism (Shohamy, Ben-Rafael \& Barni 2010), and comparative aspects (Coluzzi 2012). However, they are all based on two common foundations: (1) they use written language in the landscape as a primary source of data; (2) that they analyze the data with regard to the presence, status or functions of minority languages (Gorter, Marten \& van Mensel 2012: 3). Such flexible, all-encompassing approach has certainly contributed to the enormous popularity of linguistic landscape in a variety of disciplines and practical applications.

\section{Intercultural Competence Development}

A recent study (Spitzberg \& Changnon 2010) demonstrates that terms such as intercultural competence, intercultural effectiveness, and intercultural adaptation trace back to the 1970s and 1980s. At that time various efforts were undertaken to develop a list of intercultural competence characteristics. In the 1990s a range of elaborate conceptual models of intercultural competence (e.g., Byram 1997, Byram, Nichols \& Stevens 2001, Hajek \& Giles 2003) started to emerge. They mainly included different theoretical perspectives and methodologies that were reflected both in simple models involving only one dimension, and more complex ones that incorporated multiple dynamic agents involved in intercultural competence. Due to the proliferation of such studies, a number of different definitions related to intercultural competence was proposed in literature of that time, frequently under different labels.

For example, Heywood (2002: 10) defines intercultural literacy as "understanding, competencies, attitudes, language proficiencies, participation and identities necessary for successful cross-cultural engagement", which focuses on gaining knowledge rather than skills. Another definition of intercultural effectiveness (Stone 2006: 338) views it as "the ability to interact with people from different cultures so as to optimize the probability of mutually successful outcomes". Yet another definition (Hunter, White \& Godbey 2006: 270) proposes conceptualization of global competence, i.e. "having an open mind while actively seeking to understand cultural norms and expectations of others, leveraging this gained knowledge to interact, communicate and work effectively outside one's environment". Those attempts demonstrated that any comprehensive measures applied in this context should be multidimensional in nature. 
In 2004 Darla Deardorff observed that problems involved in defining intercultural competence stem from a multitude of components that play significant roles in this concept. This observation inspired her to conduct a comprehensive investigation (Deardorff 2004, 2006, 2010) in order to identify the components that should be incorporated in this notion. Her outcome-based definition defines intercultural competence as "the ability to communicate effectively and appropriately in intercultural situations based on one's intercultural knowledge, skills and attitudes" (Deardorff 2006: 247). It has drawn international attention and achieved wide consensus among intercultural scholars.

Deardorff's definition is accompanied by an extensive, multidimensional, cyclical model, presented in the Figure 1, which visualizes development of intercultural competence from the personal to interpersonal level of interactions as progress from individual internal outcomes, characterized by personal intercultural reflection and attitudes, to external outcomes, which result in effective interaction in intercultural contexts. Altogether Deardorff's research identifies over twenty elements of intercultural competence, including knowledge, skills, attitudes, comprehension, tolerance, etc., which were agreed upon by international scholars and practitioners in the field.

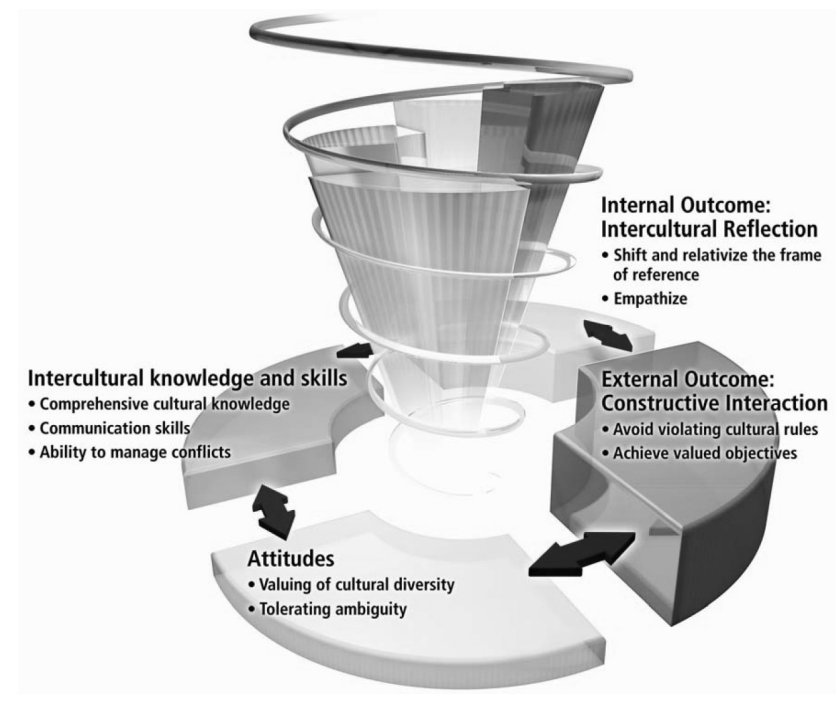

Figure 1. Deardorff's Intercultural Competence Learning Spiral

The model presumes that the development of IC skills is an on-going learning process that involves curiosity and discovery, which are necessary to transform one's attitude, knowledge, and skills to become sensitive to cultural differences in situations where language functions as a means of interaction and communication. This is congruent with Byram's view, which puts the skill of discovery and interaction, 
i.e. "the ability to acquire new knowledge of a culture and cultural practices and the ability to operate knowledge, attitudes and skills under the constraints of real-time communication and interaction" (Byram, Gribkova \& Starkey 2002: 14), among basic skills involved in intercultural competence development.

Therefore, a fundamental element in intercultural competence development is an opportunity to discover and evaluate as well as to analyze and interpret various phenomena that are related to other cultures. The acquisition of intercultural competence, including knowledge, comprehension, and skills takes place through discovery, interaction, and interpretation of other cultures manifestations. They form a key component in the practice of intercultural competence development.

\section{Situated, authentic, connected learning}

This study discusses relevance of linguistic landscape approach to the intercultural competence development in the context of situated learning. As proposed by Lave and Wenger (1991), situated learning takes place in appropriate and meaningful contexts. Exploration of linguistic landscape enables students to act as apprentices in the process of hands-on exploration of cultural diversity, which results in their increased participation in the learning community. For that reason, the linguistic landscape methodology is perfectly suited to such activities, since it situates and connects learners in the educational process.

Furthermore, implementation of language landscape activities allows for informal learning which can be basically defined as "any activity involving the pursuit of understanding knowledge or skill that occurs without the presence of externally imposed curricular criteria" (Livingstone 1999: 4). It should be noted that learning activities discussed in this paper fall into the sub-category of informal education, as distinguished by Livingstone (Ibid.), because they are conducted under the guidance of institutionally-recognized instructor. This exemplifies a transition from the knowledge production paradigm to the knowledge navigation paradigm (Brown 2005), where formal and informal techniques are mixed and the traditional teacher's role changes to that of a coach and mentor.

Another attribute particularly relevant to linguistic landscape implementation in education is the aspect of authentic learning (Donovan, Bransford \& Pellegrino 1999). It implies that learning should be centered around authentic tasks that enable students "to explore, discuss, and meaningfully connect concepts and relationships that are relevant to the real-world and are meaningful to the students". As discussed in this study, while investigating a linguistic landscape students are directly involved in exploration and inquiry of cultural diversity, hence they gain opportunities to pursue meaningful problems and become engaged in social discourse. 
This aspect is closely related to the concept of connectivism (Siemens 2004). It views the learning process as focused on connecting specialized information sets collected by individuals involved in education. In the outcome, "connections that are created in this process enable learners to gain new knowledge, which is more than their current state of knowing." (Ibid.) In this study the personal experience of individuals involved in an investigation of cultural diversity is fed back into a shared linguistic landscape to create a network of knowledge that provides further learning to all participants involved in the process. This cycle of knowledge development enables learners to gain new knowledge through the connections they have formed.

\section{In-the-field implementation}

This paper discusses learning activities based on empirical discovery, analysis, and interpretation of linguistic landscape aimed at intercultural competence development. It is based on pilot studies conducted both in foreign and local contexts. In the context of foreign environment, testing was conducted during the second edition of SILCC Summer Institute hosted by the University of Savoy in Chambery (Walinski 2013a). In the context of local environment, testing was conducted at the Institute of English Studies of the University of Lodz (Walinski 2013b). In both cases the object of study concerned only migrant minority languages whose visibility stems from mixing different cultures in the modern Europe. The unit of analysis for linguistic landscape examination was specified broadly as "any visible foreign language sign that could be spotted", including both outdoor and indoor locations. Although the data collection in both cases was conducted with implementation of mobile learning (Ally 2009), similar activities can be conducted with note taking. Transfer of foreign language signs and their respective locations to a single, commonly shared map of linguistic landscape can be executed with the use of Google Maps - a higly popular web service, which enables marking locations on electronic maps, and allows for public sharing of such resources.

Implementation of such activities requires ca. 180 minutes ( 4 teaching hours), but it can be divided into 2-3 shorter sessions, according to the following scenario:

1. Initial tutoring and instruction

a) Discussion on the cultural diversity in the selected region. Collection of students predictions about foreign languages manifested in the location of exploration (15 min.)

b) Explanation of the linguistic landscape methodology and the aim of activities. Assignment of exploration quadrants to individual students or pairs (15 min.) 
2. Empirical exploration session (60 min.)

3. Data collection and discussion

a) Data collection and mapping of the linguistic landscape into a common shared map in Google Maps (45 min.)

b) Comparison of predictions to empirical data acquired through hands-on exploration, including the discussion on the differences between intuitive perception of cultural diversity and empirical findings. Summary of results (45 min.)

Such activities demonstrate that subjective awareness of cultural diversity depends on personal cognitive perspectives. The initial discussion is intended to identify students' starting cultural awareness. The exploration stage involves authentic, situated, informal learning. A tangible outcome of such activities is a shared map that included linguistic sign locations, which reflects the linguistic landscape. The final discussion is based on comparing the emergent linguistic landscape with earlier predictions. It typically evidences, through connected learning experience, a discrepancy between the subjective predictions and the objective reality revealed via hands-on empirical examination of the linguistic landscape. Moreover, it enables to identify popular beliefs and stereotypes that play a major role in our subjective perception of cultural diversity. In the outcome, such activities show that curiosity and openness towards other cultures result in a change of cultural diversity cognition, which elevates intercultural competence of students.

\section{Observations}

A fundamental observation that emerges from the conducted pilot studies is that languages observed in the location of exploration, both in foreign and local contexts, differ from students' predictions as to their occurrence and prevalence. Generally, top positions in students' predictions are occupied by popular European languages, i.e. English, French, German, Italian, and Spanish. The linguistic landscape reveals that not all of those languages are as strongly visible as it is expected. Moreover, it exposes elements that are less noticeable, for example a wide variety of Asian cultures (see Waliński 2013a). Such differences indicate that our perception of the cultural diversity is significantly influenced by socio-cultural frames (Goffman 1974). What we identify as important in the surroundings is what we recognize, and what is not recognized escapes our perception. It indicates that our personal attitudes exert a significant influence on the sensitivity of perception and resulting cognition of cultural diversity. The objective cultural diversity reflected in a map of linguistic landscape usually does not overlap with predictions, which are influenced by intuitive cognitive biases (Gilovich, Griffin \& Kahneman 2002).

It leads to a conclusion that the subjective cultural diversity depends to some extent on cultural stereotypes and personal perspectives. For that reason, cultures 
subjectively recognized as important not only tend to occupy higher positions in cognitive representations of cultural diversity, but are also more easily discernable for us in the surrounding linguistic reality. Cultures subjectively recognized as less prominent not only tend to occupy lower positions in cognitive representations of cultural diversity, but are also less discernable for us in the surrounding linguistic reality. This observation goes along the lines of Piaget's theory of schemata (Piaget \& Inhelder 1958), Papert's theory of constructionism (Harel \& Papert 1991), constructivistic assertions that learning is based both upon experience of external objects and former knowledge (Jonassen 1991). It is also congruent with recent developments of cognitive science on the level of mental construal of distant and near phenomena (Trope \& Liberman 2010).

Pointing out and summarizing these observations, especially when they are supported by a map of objective linguistic landscape created by students themselves through connected learning, results in the change of students' stance to other cultures and raises their cultural awareness. As pointed out by Deardorff (2006: 255) attitudes of openness, respect, curiosity and discovery for acquiring and processing knowledge about other cultures are fundamental to the development of the much desired internal outcomes of intercultural competence. Consequently, broadening of cultural diversity horizons is a sound staring point for further intercultural competence development.

\section{Conclusion}

Empirical exploration of cultural diversity based on the linguistic landscape methodology provides authentic environmental cues for better understanding of the cultural diversity phenomenon, which results in a much grater contextualization of learning than would ever be achievable in the traditional teaching process. Moreover, application of the linguistic landscape methodology provides tangible empirical evidence about the variety of languages that are relevant in the increasing cultural diversity of the globalizing world, which can be used in fruitful discussions on this topic.

This study signals a ready made scenario for authentic, informal, situated learning activities implemented in the framework of connectionism, which can be employed for intercultural competence development. They can additionally be augmented with the use of m-learning (Walinski 2013b) which results in additional benefits observed in education conducted in such manner (JISC 2011). This paper points to the potential for linguistic landscape applications in foreign language teaching, especially in the context of intercultural competence development practice.

The aspect of intercultural competence in the SLA is of utmost importance, since the ability to deal with cultural diversity is no longer required only of 
business professionals working in international settings, but has become a basic qualification required of individuals to act productively in the modern world. This has already been confirmed in research (Deardorff and Hunter 2006, Hulstrand 2008) pointing out that the ability to handle interaction in culturally diverse environments is a major skill employers seek. In more general terms, as emphasized by Biggs (2003), contextualized teaching of intercultural competence is among key components of the contemporary tertiary education.

\section{References}

Ally, M. (Ed.) 2009. Mobile Learning: Transforming the Delivery of Education and Training. Edmonton: AU Press.

Backhaus, P. 2007. Linguistic Landscapes: A Comparative Study of Urban Multilingualism in Tokyo. Clevedon: Multilingual Matters.

Biggs, J. 2003. Teaching for Quality Learning at University (2nd edition). Buckingham: Open University Press.

Brown, T. 2005. Beyond constructivism: Exploring future learning paradigms. Available at: http:// www.dreamland.co.nz/educationtoday/Tom_Brown_Beyond_Constructivism.pdf

Byram, M. 1997. Teaching and assessing intercultural communication competence. New York: Multilingual Matters.

Byram, M., Gribkova, B., Starkey, H. 2002. Developing the intercultural dimension in language teaching: A practical introduction for teachers. Strasbourg: Council of Europe.

Byram, M., Nichols, A., Stevens, D. 2001. Developing intercultural competence in practice. New York: Multilingual Matters.

CEDEFOP. European Centre for the Development of Vocational Training 2009. Skills for Europe's Future: Anticipating Occupational Skills Needs. Luxembourg: Office for Official Publications of the European Communities.

CEDRPC. Committee for Economic Development Research and Policy Committee 2006. Education for global leadership: The importance of international studies and foreign language education for U.S. economic and national security. Washington, DC: Committee for Economic Development.

Cenoz, J., Gorter D. 2006. Linguistic landscape and minority languages. International Journal of Multilingualism, 3, 67-80.

Cenoz, J., Gorter D. 2008. Linguistic landscape as an additional source of input in second language acquisition. IRAL-International Review of Applied Linguistics in Language Teaching, 46, 267-287.

Coluzzi, P. 2012. Multilingual Societies vs Monolingual States: The Linguistic Landscapes in Italy and Brunei Darussalam. In D. Gorter, H.F. Marten \& L. van Mensel, L. (Eds.), Minority Languages in the Linguistic Landscape. Hampshire: Palgrave Macmillan.

Deardorff, D.K. 2004. The Identification and Assessment of Intercultural Competence as a Student Outcome of Internationalization at Institutions of Higher Education in the US. Doctoral dissertation. Raleigh, NC: NCSU.

Deardorff, D.K. 2006. Identification and Assessment of Intercultural Competence as a Student Outcome of Internationalization. Journal of Studies in International Education, 10, 241266.

Deardorff, D.K. (Ed.) 2010. The SAGE Handbook of Intercultural Competence. Los Angeles: SAGE Publications. 
Deardorff, D.K., Hunter, W. 2006. Educating global-ready graduates. International Educator, $15,72-83$.

Donovan, M.S., Bransford, J.D., Pellegrino, J.W. (Eds.) 1999. How People Learn: Bridging Research and Practice. Washington, DC: National Academies Press.

Extra, G., Gorter, D. (Eds.) 2008. Multilingual Europe: Facts and Policies. Berlin: Mouton de Gruyter.

Gilovich, T., Griffin, D., Kahneman, D. (Eds.) 2002. Heuristics and biases: The psychology of intuitive judgment. New York: Cambridge University Press.

Goffman, E. 1974. Frame Analysis: An essay on the organization of experience. Cambridge, MA: Harvard University Press.

Gorter, D. 2006. Further Possibilities for Linguistic Landscape Research . In: D. Gorter (Ed.) Linguistic Landscape: A New Approach to Multilingualism (pp. 81-89). Clevedon: Multilingual Matters.

Gorter, D., Marten, H.F., van Mensel, L. (Eds.) 2012. Minority Languages in the Linguistic Landscape. Hampshire: Palgrave Macmillan.

Hajek, C., Giles, H. 2003. New directions in intercultural communication competence: The process model. In J.O. Greene, B.R. Burleson (Eds.), Handbook of communication and social interaction skills (pp. 935-957). Mahwah, NJ: Lawrence Erlbaum.

Harel, I., Papert, S. 1991. Constructionism. Norwood, NJ: Ablex.

Heywood, M. 2002. From international to intercultural: Redefining the international school for a globalized world. Journal of Research in International Education, 1, 9-31.

Hulstrand, J. 2008. Building a fluent workforce. International Educator, 17, 24-31.

Hunter, B., White, G., Godbey, G. 2006. What Does It Mean to Be Globally Competent? Journal of Studies in International Education, 10, 267-285.

JISC 2011. JISC InfoNet. Mobile Learning infoKit. JISC Advance, UK.

Jonassen, D.H. 1991. Evaluating constructivistic learning. Educational Technology, 31, 28-33.

Kallen, J. 2009. Tourism and representation in the Irish linguistic landscape. In E. Shohamy, D. Gorter (Eds.), Linguistic Landscape: Expanding the Scenery. London: Routledge.

LACE 2006. Languages and Cultures in Europe. Study of the intercultural skills taught in foreign languages courses at each stage of compulsory education and training in the European Union. Final Report. EAC/25/06, 14 Dec 2006.

Landry, R., Bourhis, R.Y. 1997. Linguistic landscape and ethnolinguistic vitality: An empirical study. Journal of Language and Social Psychology, 16, 23-49.

Lave, J., Wenger, E. 1991. Situated learning: Legitimate peripheral participation. Cambridge: Cambridge University Press.

Livingstone, D.W. 2001. Adults' Informal Learning: Definitions, Findings, Gaps and Future Research. Available at: https://tspace.library.utoronto.ca/bitstream/1807/2735/2/21adultsinformallearning.pdf

Nunes, P., Onofri, L., Gorter D., Cenoz, J. 2008. Language diversity in urban landscapes: An econometric study. Fondazione Eni Enrico Mattei Working Papers. Working Paper 199. Available at: http://www.bepress.com/feem/paper199

Piaget, J., Inhelder, B. 1958. The growth of logical thinking from childhood to adolescence: An essay on the construction of formal operational structures. London: Routledge.

RHLEFM 2008. Report of the High Level Expert Forum on Mobility. Making learning mobility an opportunity for all. Strasbourg: Council of Europe. Available at: http://ec.europa.eu/ education/doc/2008/mobilityreport_en.pdf

Shohamy, E., Gorter, D. (Eds.) 2009. Linguistic Landscape: Expanding the Scenery. London: Routledge.

Shohamy, E., Ben-Rafael, E., Barni, M. (Eds.) 2010. Linguistic Landscape in the City. Bristol: Multilingual Matters. 
Siemens, G. 2004. Connectivism: A learning theory for the digital age. Elearnspace. Available at: http://www.elearnspace.org/Articles/connectivism.htm

Sloboda, M. 2009. State ideology and linguistic landscape: A comparative analysis of (post)communist Belarus, Czech Republic and Slovakia. In E. Shohamy \& D. Gorter (Eds.), Linguistic Landscape: Expanding the Scenery. London: Routledge.

Spitzberg, B.H., Changnon, G. 2010. Conceptualizing Intercultural Competence. In: D. Deardorff (Ed.), The SAGE Handbook of Intercultural Competence. Los Angeles: SAGE Publications.

Stone, N. 2006. Conceptualising Intercultural Effectiveness for University Teaching. Journal of Studies in international Education, 10, 334-356.

Trope, Y., Liberman, N. 2010. Construal-Level Theory of Psychological Distance. Psychological Review, 117, 440-463.

UNESCO 2001. Universal Declaration on Cultural Diversity. UNESCO Records of the General Conference, 31st Session, Paris.

UNESCO 2005. Convention on the Protection and Promotion of the Diversity of Cultural Expressions. UNESCO Records of the General Conference, 33rd Session, Paris.

Walinski, J. 2013a. Application of new media for content creation in the linguistic landscape approach to increasing cultural awareness in foreign environment. In B. Lewandowska-Tomaszczyk, M. Kopytowska, J. Osborne, J. Schmied, K. Ymlu (Eds.), Languages and Cultures in Contact and in Contrast. Chambery: University of Savoy Press.

Walinski, J. 2013b. Media creation and sharing in informal, situated, authentic mobile learning for local cultural diversity investigation. In I.A. Sanchez (Ed.), Proceedings of IADIS Mobile Learning Conference. Lisbon: Portuguese Open University. 